\title{
CLL/S detuned compensation network for electric vehicles wireless charging application
}

\author{
Ahmad Fuad Abdul Aziz, Mohd Fakhizan Romlie, Tun Zainal Azni Zulkifli \\ Department of Electrical and Electronics Engineering, Universiti Teknologi PETRONAS, Malaysia
}

\begin{abstract}
Article Info
Article history:

Received Feb 27, 2019

Revised Apr 28, 2019

Accepted Jun 13, 2019

Keywords:

Compensation circuit

ICPT

Inductor detuned

Maximum current rating

Zero voltage switching

ABSTRACT

An electric vehicle (EV) can be charged wirelessly through an inductively coupled power transfer system where the system resonates the inductive coupling coil at the operating frequency by means of a compensation network. However, the resonant behaviour implies overcurrent in the inverter MOSFETs during uncoupled and high load resistor conditions, which affect to the inverter MOSFETs failure whenever the current exceeds their maximum current rating. Therefore, this paper presents a CLL/S detuned compensation network for EV wireless charging application to limit the inverter current during the uncoupled state and open circuit load conditions. The proposed compensation consists of a series capacitor and parallel inductor at the primary side and series capacitor at the secondary side. By using Kirchhoff Voltage Law (KVL) analysis, the primary side is detuned to inductive behaviour to ensure zero voltage switching (ZVS), and the secondary side remains at natural resonant tuning. From the simulation analysis, the slight increase of the parallel inductor value at the primary side can limit of the inverter current at uncoupled and high load resistor conditions. The proposed system also offers higher efficiency than the seriesseries detuned compensation and slightly lower than the double-sided LCC compensation network at different coupling factor.
\end{abstract}

Copyright (C) 2019 Institute of Advanced Engineering and Science. All rights reserved.

\section{Corresponding Author:}

Mohd Fakhizan Romlie,

Department of Electrical and Electronics Engineering,

Universiti Teknologi PETRONAS,

Seri Iskandar, Perak, Malaysia.

Email: fakhizan.romlie@utp.edu.my

\section{INTRODUCTION}

Wireless charging is an upgraded technology to charge electric vehicles (EV) instead of the plug-in method since it promotes convenience to the EV drivers [1]. The wireless charger pad will charge EV automatically when the vehicle parks over the pad [2]. This system is safer than wired charging in terms of electricity exposure as an insulated plate covers and seals the transmission coil [3]. Most of EV wireless charging systems are inductively coupled power transfer (ICPT) where the magnetic resonance field transfers the electric power [4]. The system consists of transmitter and receiver coils, and they locate near to each other. Both coils must operate at a similar resonant frequency to transfer energy efficiently [5]. Thus, a compensation circuit assists the coils to achieve resonance.

Two-capacitor compensations are famous compensations in the two-coil resonator system of ICPT. Each coil utilizes one compensated capacitor. The capacitor connection at primary and secondary coils are including, series-series (SS), series-parallel (SP), parallel-series (PS) or parallel-parallel (PP) [6]. The SS compensation is the most practical among them for EV wireless charging application as it offers high tolerance of misalignment and independent from load variation [7]. However, these capacitors suffer from high voltage stress at resonance [8]. An extended compensation topology such as Pi-network or T-network connection is introduced by adding inductor in order to distribute voltage stress between passive elements 
and coils [9]. Besides, the T-network and Pi-network generate constant voltage output and constant current output, respectively [10]. Thus, their resonant frequencies are irrelevant to the coupling coefficient [11]. For example, LCL, LCC-S, S-CLC, LC-S and double-sided LCC are compensation structures presented in previous articles [11-15]. Although all these compensations are tuned to zero voltage switching (ZVS), the coupling coil size limits the parameter of compensation elements.

The ZVS operation is a necessary criterion to obtain soft switching in the inverter power MOSFETs $[16,17]$. Based on previous research, the compensation circuit must be tuned slightly to the inductive region from the resonance point by increasing the secondary capacitor value or reducing the coil self-inductance parameter slightly [15]. Maintaining unity power factor or zero-phase angle (ZPA) operation in square wave input voltage is challenging since most of the designed circuit is based on fundamental harmonic analysis (FHA) [18]. Furthermore, the voltage transition of MOSFET between on and off produces slew rates that leads to significant switching loss if high input current at switching point $[15,19]$. Moreover, the ZVS is preferable than zero current switching (ZCS) since most of the power MOSFET embeds flywheel diode that conducts reverse current in the transistor [15]. Even though the ZVS tuning is approximate to the natural resonant frequency, the ICPT still draws overcurrent issue from the inverter, especially at uncoupled and high load resistor conditions $[20,21]$. Consequently, the excessive current brakes down the inverter since the current exceeds the MOSFET maximum current rating and damages the MOSFETs [22].

There are passive and active control techniques that can prevent excessive current through the inverter. The passive methods are including compensation structure of double-sided LCC and SS detuning $[15,21]$. The inverter current flows to the double-sided LCC compensation is directly proportional to the coupling factor. Nevertheless, the current contains high total harmonic distortion, which leads to hard switching in the inverter [23]. On the other hand, the capacitor detuning technique of SS compensation changes the value of the capacitors so that the primary side tune to inductive characteristic while the secondary circuit tune to capacitive characteristic. It benefits the system to regulate power transfer at a wide range of coupling factor and prevent the excessive current issue. Unfortunately, the detuning approach exacerbates the power transfer efficiency. Otherwise, active control methods such as phase shifting at the $\mathrm{H}-$ bridge inverter and duty cycle variation at DC boost converter require feedback information from the receiving side, which utilizes wireless communication systems [20,24]. Hence, it implies to high possibility of receiver data to be interrupted due to signal interference with a strong magnetic field [25]. Thus, this problem deteriorates ICPT system reliability.

In this study, a novel compensation scheme of CLL/S will be proposed to constraint the inverter current to the coupling coils as according to maximum rating current of power MOSFET inverter. The proposed compensation consists of a series capacitor and a parallel inductor connected in L-network at primary circuit while a series capacitor at the secondary circuit. It only requires the inductor parameter tuning at the primary circuit to match the MOSFET current rating without affecting its power transfer efficiency. This paper addressed four objectives which are understanding the input current characteristic based on mutual inductance equivalent circuit model at series-series resonant state, deriving detuned parameter of proposed compensation network using KVL circuit analysis on reactance representation of the compensation network and the equivalent circuit model, analysing input current characteristic at different detuning factor and comparing the proposed power transfer efficiency with previous compensation networks that consider overcurrent issue at uncoupled condition.

\section{ICPT FUNDAMENTAL STUDY}

Before deriving and analysing the proposed compensation network, the ICPT system need to be simplified in order to comprehend the input current characteristic at resonant state with varying coupling coefficients. Figure 1 illustrates a basic configuration of ICPT which covers DC voltage source, inverter, impedance matching network (IMN) or compensation circuit, coupling coils, rectifier and battery. The DC voltage source can represent the output voltage of the boost converter at the primary side. A square wave voltage generated by the inverter, vs, can be defined in Fourier expansion form as

$$
v_{S}(t)=\frac{4}{\pi} \sum_{k=1}^{\infty} \frac{\sin ((2 k-1) \omega t)}{2 k-1}
$$

$\omega$ and $t$ is angular frequency and time, respectively. Total summation of odd harmonics produces approximately a square wave signal. At the secondary side, an equivalent end load resistor, $R_{E}$ replaces the batteries and rectifier. Considering $R_{E}$ accepts any voltage levels to disregard DC buck converter function at the secondary side. Thus, $R_{E}$ based on equivalent resistance battery, $R_{\text {battery }}$ and receiver rectifier is [11]

Int J Pow Elec \& Dri Syst Vol. 10, No. 4, Dec 2019 : 2173 - 2181 


$$
R_{E}=\frac{8}{\pi} R_{\text {Battery }}
$$

This simplification model is presumed for studying mutual inductance of the coupling coils, especially the excitation voltage characteristic at the secondary coil and designing the proposed compensation network.

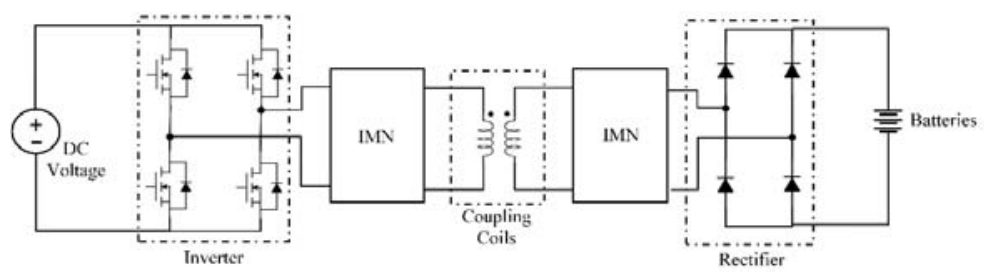

Figure 1. Simplified ICPT system. (IMN is impedance matching network)

\subsection{Mutual inductance of coupling coils}

According to mutual inductance principle, when two separated coils locate near to each other, additional excitation voltages appear to both coils caused by mutual inductance phenomena where the mutual inductance is defined as

$$
M=k \sqrt{L_{1} L_{2}}
$$

$M, k, L_{1}$ and $L_{2}$ are mutual inductance, coupling coefficient, primary coil self-inductance and secondary coil self-inductance, respectively. Both primary and secondary coils consist of excitation voltages derived from the multiplication of mutual inductance reactance, $j \omega M$ and current of the opposite side. Figure 2 shows an equivalent circuit model of the coupling coil in phasor form based mutual inductance principle. The voltage across at primary, $v_{l}$ and secondary circuit, $v_{2}$ are

$$
\begin{aligned}
& v_{1}=j \omega L_{1} I_{1}-j \omega M I_{2} \\
& v_{2}=-j \omega L_{2} I_{2}+j \omega M I_{1}
\end{aligned}
$$

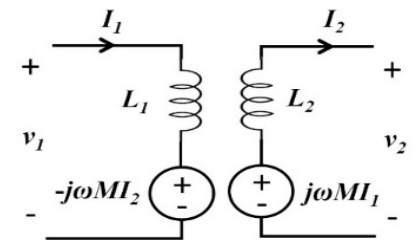

Figure 2. Mutual inductance model

$I_{1}$ and $I_{2}$ are the primary and secondary current flow through the coil. Because both excitation voltages, $j \omega M I_{n}$, rely on opposite current, $I_{n}$, the excitation voltage of the primary side can be replaced with a reflected impedance to the primary side, $Z_{R}$. Let's say, $v_{2}=Z_{\text {Load. }} . I_{2}$, then

$$
\begin{aligned}
I_{2} & =\frac{j \omega M I_{1}}{Z_{\text {Load }}+j \omega L_{2}} \\
& =\frac{j \omega M I_{1}}{Z_{s}},
\end{aligned}
$$

where $Z_{s}$ is the total impedance of the secondary side. Substitute $I_{2}$ in (2) with (6). Then the primary voltage, $v_{l}$ will be

CLL/S detuned compensation network for electric vehicles wireless charging ... (Ahmad Fuad Abdul Aziz) 


$$
\begin{aligned}
v_{1} & =j \omega L_{1} I_{1}+\frac{(\omega M)^{2}}{Z_{S}} I_{1} \\
& =\left(j \omega L_{1}+Z_{R}\right) I_{1} .
\end{aligned}
$$

From (7), the $Z_{R}$ is inversely proportional to the $Z_{S}$ and directly proportional to $(\omega M)^{2}$. Figure 3 illustrates a phasor model of coupling coil after $Z_{R}$ replaces the primary coil excitation voltage, $j \omega M I_{2}$. In order to understand the characteristic of secondary voltage, series capacitors need to compensate both selfinductance coils. At resonance coupling, the current flows through the capacitor and coil is considered as short-circuited. Hence, the $I_{l}$ varies concerning $Z_{R}$ values. Then, the voltage at the secondary coil is induced based on two factors, which are the primary current, $I_{l}$ and mutual inductance reactance, $j \omega M$.

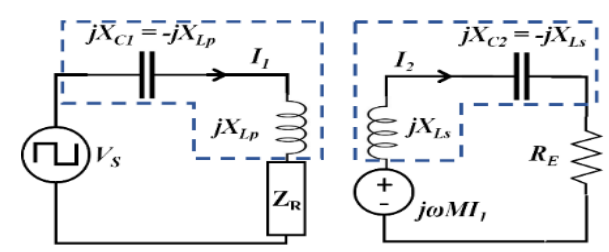

Figure 3. Equivalent circuit model of ICPT system for series-series compensation network

Figure 4 shows the secondary excitation voltage, $\omega M I_{I}, I_{I}$ and $\omega M$ at different coupling coefficients, $k$. The $I_{l}$ current decreases exponentially when $k$ increases, whereas the $I_{l}$ reciprocal curve lessens as the $Z_{R}$ value gains. The $\omega M$ graph is a linear increase, and its gradient depends on the coil quality factor and its physical structure, including coil geometry, size, and material [5]. On the other hand, the $I_{l}$ curve can be manipulated by implementing passive control or active control techniques that have been mentioned in the introduction section. Hence, the proposed CLL/S compensation network will focus on altering the $I_{l}$ characteristic at varying coupling coefficient.

As refer to Figure 4, the $I_{l}$ curve escalates gradually when the secondary circuit reaches an open circuit condition. The $Z_{R}$ at the primary circuit is inversely proportional to the total impedance of the secondary circuit, $Z_{s}$. When the $Z_{s}$ increases due to $R_{E}$ increment, the $Z_{R}$ decreases. As a result, the primary current increases gradually during charging the battery and increases tremendously as coupling weaken or reduces. The latter circumstance, which occurred when the receiver coil is moving away from the transmitter coil while the $I_{l}$ is still flowing in the transmitter coil, must avoid since overcurrent can damage the MOSFETs in H-bridge inverter due to the drain-to-source current exceeding the maximum current rating of MOSFET.

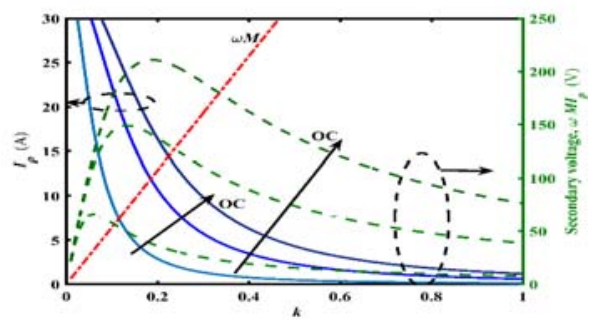

Figure 4. Characteristic of excitation voltage from the secondary side obtained from primary current and mutual inductance reactance

\section{CLL/S COMPENSATION NETWORK}

In this proposed system, the current can be reduced during the uncoupled condition by detuning the compensated inductive at the primary side. A CLL compensation structure is a T-network structure where compensated capacitor, $C_{1}$ is connected in series to self-inductance of the primary coil, $L_{P}$ while compensated inductor, $L_{1}$ is in parallel to $L_{P}$ as illustrated in Figure 5. A compensated capacitor, $C_{2}$ at the secondary side

Int J Pow Elec \& Dri Syst Vol. 10, No. 4, Dec 2019 : 2173 - 2181 
connects in series to self-inductance of the secondary coil, $L_{S}$ in order to generate constant output voltage to the end load and minimize the utilization of passive components at the pickup coil area. The $C L$ compensation network is selected since the detuning element of $L_{l}$ in the $C L$ network will not lessen the primary coil current [26]. Thus, it affects the excitation voltage of the secondary coil.

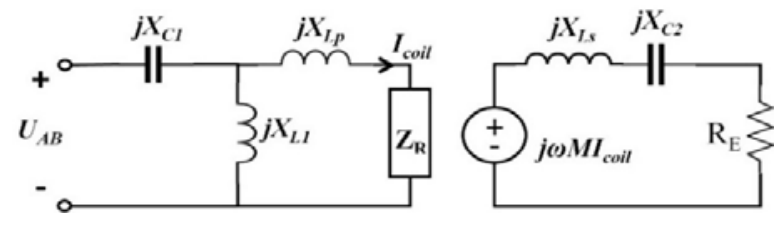

Figure 5. Proposed CLL/S compensation network

Derivation of CLL compensation network begins by defining the reactance of capacitor, $X_{c}$ and inductor, $X_{L}$ which is

$$
\begin{aligned}
& X_{C}=\frac{1}{\omega C} \\
& X_{L}=\omega L
\end{aligned}
$$

where $\omega$ is angular frequency. The proposed network must be tuned to inductive characteristic since to maintain ZVS in MOSFET inverter. The tuning must move near to natural resonant frequency for utilizing magnetic resonant coupling behaviour in the system. Thus, to obtain natural resonance frequency in the primary side, the coil is assumed to be uncoupled where the $Z_{R}$ is equal to zero value. Therefore, total reactance in the primary side, $X_{T}$ must be zero

$$
\begin{aligned}
-j X_{C}+\left(j X_{L p} \| j X_{L 1}\right) & =X_{T}=0 \\
X_{C} & =\frac{X_{L 1} X_{L p}}{\left(X_{L 1}+X_{L p}\right)}
\end{aligned}
$$

$X_{L l}, X_{L p}, X_{C}$ are reactance of compensated inductor, $L_{1}$, self-inductance coil, $L_{P}$, and compensated capacitor, $X_{C}$. By replacing reactance terms in (10) with (8) and (9), the natural resonant frequency of CLL compensation is

$$
\omega=\sqrt{\frac{1}{L_{1} C_{1}}+\frac{1}{L_{P} C_{1}}}
$$

If the value of $L_{P}$ is equal to $L_{l}$, the value of $C$ is

$$
\begin{aligned}
-j X_{C} & =-j \frac{X_{L p}}{2} \\
C & =\frac{2}{\omega^{2} L_{P}}
\end{aligned}
$$

All compensated reactance parameters in the circuit are referring to reactance $X_{L p}$ parameter. The critical parameter to investigate is the magnitude and phase angle of input current, $I_{l}$, since the concern of this proposed structure to limit the current flow through the MOSFETs inverter by tuning to inductive behaviour. Thus, the $I_{l}$ can be obtained by using Kirchhoff Voltage Law (KVL) to the primary circuit,

$$
I_{1}=\frac{2 U_{A B}\left(Z_{R}+j\left(X_{L p}+X_{L 1}\right)\right)}{\left(X_{L p}^{2}-X_{L p} X_{L 1}\right)+j Z_{R}\left(2 X_{L 1}-X_{L p}\right)}
$$


and the $I_{l}$ angle concerning voltage source, $U_{A B}$

$$
\begin{gathered}
\alpha_{1}=\arctan \frac{X_{L p}\left(X_{L p}^{2}-X_{L 1}^{2}\right)-Z_{R}^{2}\left(2 X_{L 1}-X_{L p}\right)}{2 Z_{R} X_{L 1}^{2}} \\
=\arctan \frac{\omega^{2} L_{P}\left(L_{P}^{2}-L_{1}^{2}\right)-Z_{R}^{2}\left(2 L_{1}-L_{P}\right)}{2 Z_{R} \omega L_{1}^{2}}
\end{gathered}
$$

To achieve ZVS operation, the $I_{l}$ angle, $\alpha_{l}$ must less than $0^{\circ}$ to indicate current lagging condition. Therefore,

$$
Z_{R}^{2}\left(2 L_{1}-L_{P}\right)>\omega^{2} L_{P}\left(L_{P}^{2}-L_{1}^{2}\right)
$$

The value of $L_{l}$ can be calculated from (13) by assuming $Z_{R}=0$

$$
\begin{gathered}
X_{L 1}=\frac{X_{L p}\left(X_{L p} I_{1}+2 U_{A B}\right)}{X_{L p} I_{1}-2 U_{A B}} \\
L_{1}=\frac{L_{P}\left(\omega L_{P} I_{1}+2 U_{A B}\right)}{\omega L_{P} I_{1}-2 U_{A B}}
\end{gathered}
$$

Meanwhile, the primary coil current, $I_{\text {Coil }}$, is

$$
I_{\text {Coil }}=\frac{2 U_{A B} X_{L 1}}{Z_{R}\left(2 X_{L 1}-X_{L p}\right)+j\left(X_{L 1} X_{L p}-X_{L p}^{2}\right)}
$$

The $I_{\text {Coil }}$ is another concerned value where it determines the secondary side excitation voltage. Its angle will not affect the excitation voltage value, but it shifts the excitation voltage phase angle with respect to the voltage source, $U_{A B}$.

\section{SIMULATION RESULT AND ANALYSIS}

A simulation has been conducted to analyse the CLL/S compensation network using MATLAB Simulink R2018 platform. This simulation observes four main parameters, which are input current, $I_{l}$, its phase angle, $\alpha_{1}$, coil current, $I_{\text {coil }}$ as well as power transfer efficiency for varying values of compensation inductor, $L_{l}$. In simulation analysis, assumptions of the voltage source, $U_{A B}$ and equivalent load resistance, $R_{E}$ are necessary for analytical model. The series compensation capacitor at secondary side eliminates coil selfinductance reactance at secondary which remains the $R_{E}$ only. Therefore, the $Z_{S}$ in (6) is equivalent to $R_{E}$ so that the $Z_{R}$ can be estimated based on the coupling coefficient.

Table 1 listed other parameters for simulation analysis. The value is selected based on wireless charging of electric vehicle application in [27]. The $R_{E}$ value has two different value to indicate two conditions of battery charging, $5 \Omega$ is equivalent to $5 \%$ charging battery level while $200 \Omega$ is assumed to be $100 \%$ or full battery charge condition. These two values are studied since the characteristic of primary current change as the end load becomes an open circuit. In the graph results, all reactance, including the $R_{E}$, mutual inductance reactance, is normalized by primary coil self-inductance reactance.

Table 1. Parameter for CLL/S compensation network

\begin{tabular}{ccc}
\hline Parameter & Symbol & Value \\
\hline Input Voltage & $U_{A B}$ & $200 \mathrm{~V}$ \\
Operating frequency & $f$ & $85 \mathrm{kHz}$ \\
Primary coil self-inductance & $L_{P}$ & $120 \mu \mathrm{H}$ \\
Secondary coil self-inductance & $L_{S}$ & $120 \mu \mathrm{H}$ \\
Equivalent Load Resistance & $R_{E}$ & $5 \Omega / 200 \Omega$ \\
Primary compensated capacitor & $C_{I}$ & $58.4 \mathrm{nF}$ \\
Secondary compensated capacitor & $C_{2}$ & $29 \mathrm{nF}$ \\
\hline
\end{tabular}

Int J Pow Elec \& Dri Syst Vol. 10, No. 4, Dec 2019 : 2173 - 2181 
Figure 6 illustrates the normalized coil current values and its phase angle when the $L_{l}$ is varied. The base coil current, $I_{\text {Coil (base) }}$ is equivalent to voltage source squared, $U_{A B}{ }^{2}$ divided by $R_{E}$. When the battery is charging, the $R_{E}$ value increases gradually, and $Z_{R}$ decreases at the primary side. It causes high current flows to the primary circuit at resonant state, which is the ratio $X_{L 1} / X_{L p}$ equals unity. The ratio must detune to over unity value to reduce the current at the required level. The ratio must exceed than unity value to ensure lagging current in the circuit so that ZVS can be realized. Consideration of compensated inductor, $L_{l}$ is critical at high load $R_{E}\left(R_{E}=200 \Omega\right)$ because a slight change of compensated inductor leads to current drop significantly, especially at weak coupling. At low load $\left(R_{E}=5 \Omega\right)$, the variation of $L_{l}$ has less implication to $I_{\text {Coil }}$ value. For weak coupling at low load, the normalize current, $I$ Coil declines from 0.4 to $0.2 \mathrm{~A}$ when the ratio $X_{L 1} / X_{L p}$ change from 1 to 1.2. If the ratio higher than 1.2, the energy transfer between the coil becomes less effective since the current flow through the coil is inadequate to induce a strong magnetic field [26]. Therefore, the selection of compensated inductor is critical since it must reconcile between effective power transfer and limitation of current through MOSFETs inverter.

According to (13), a slight increase of $L_{l}$ will reduce the input current, $I_{l}$ to a specified value. Figure 7 illustrates the effect of input current when the $R_{E}$ increases at varying $k$. When the battery is fully charged, the input current will not exceed than the current limit at uncoupled state, as for this case, $43 \mathrm{~A}$. Meanwhile, the input impedance angles remain in the inductive region at varying coupling coefficient. The angle increases to $87^{\circ}$ as the $R_{E}$ increases. However, it is still operating in the inductive region. The low $R_{E}$ changes the input current significantly as the coupling coefficient rises since the mutual inductance reactance squared, $(\omega M)^{2}$ influences the $Z_{R}$ value more than the $R_{E}$ which result on changes to input current as $k$ increases. As the $R_{E}$ load gains, the influence of $(\omega M)^{2}$ diminishes that results on constant current supply from input current at varying $k$. Thus, the variation of $L_{l}$ can limit the current supply and preserve the MOSFETs in inverter from exceeding their maximum rating.
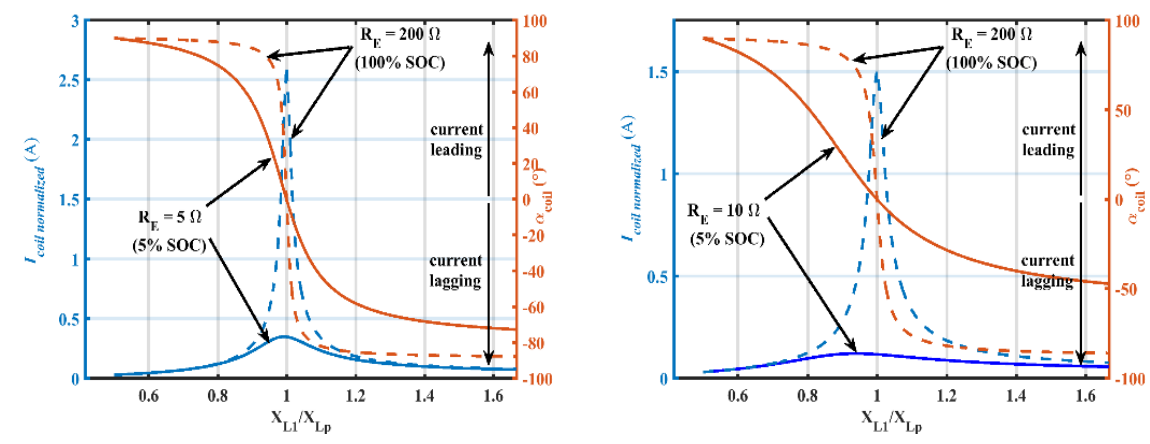

Figure 6. Normalized coil current and its phase angle characteristic at two load conditions based on ratio $X_{L 1} / X_{L p}$. (left $k=0.18$, right $k=0.32$ )
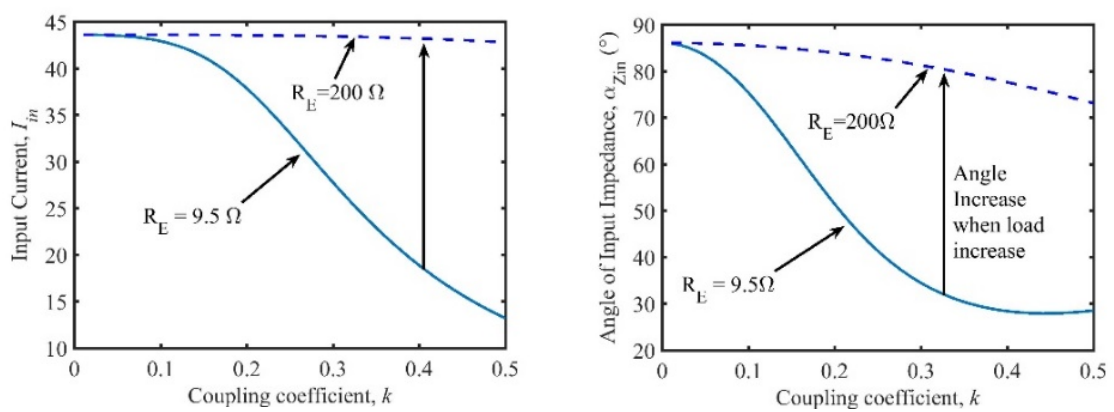

Figure 7. Input current and angle of input impedance for $L_{I}$ equal to $140 \mu \mathrm{H}\left(X_{L 1} / X_{L p}=1.167\right)$

Figure 8 shows the voltage gain at different $L_{l}$ where the peak voltages are shifting to higher $k$ as the $L_{l}$ increases but the peak voltage gain not as high as the lower $L_{l}$. When the $L_{l}$ value increment from $140 \mu \mathrm{H}$ to $160 \mu \mathrm{H}$, the current limit value decline almost half. The significant change is due to the high-quality factor in the primary circuit, where the ratio of primary impedance between the imaginary part to the real part is very

CLL/S detuned compensation network for electric vehicles wireless charging ... (Ahmad Fuad Abdul Aziz) 
high. Thus, the circuit has narrow bandwidth and sensitive to any reactance change inside the circuit. However, as the $L_{1}$ gains from $160 \mu \mathrm{H}$ to $180 \mu \mathrm{H}$, the current limit reduces almost one third or $30 \%$ of the previous value. At this time, the coil current is reaching to the saturated value of the inductive region as if the $L_{l}$ value gain more, the coil current remains consistent to a specific value as illustrated in Figure 5 . Hence, the maximum current rating of MOSFETs inverter determines the $L_{l}$ values in this compensation network.

In terms of efficiency, the proposed compensation scheme is approximately similar as the double-sided LCC and better than detuning of the SS technique. Even though the compensated inductor tunes to other value, as to match with a maximum current rating of MOSFETs in an inverter, its efficiency remain unchanged. This efficiency characteristic is simulated at low battery condition; for this case, $R_{E}$ is equal to $5 \Omega$. The proposed compensation efficiency achieves more than $80 \%$ when the coupling coefficient higher than 0.12 . The efficiency of all compensation, however, drops when the $R_{E}$ increases due to the power consumed by the battery decreases at full charge state. Still, the highest efficiency is SS tune compensation at resonant.
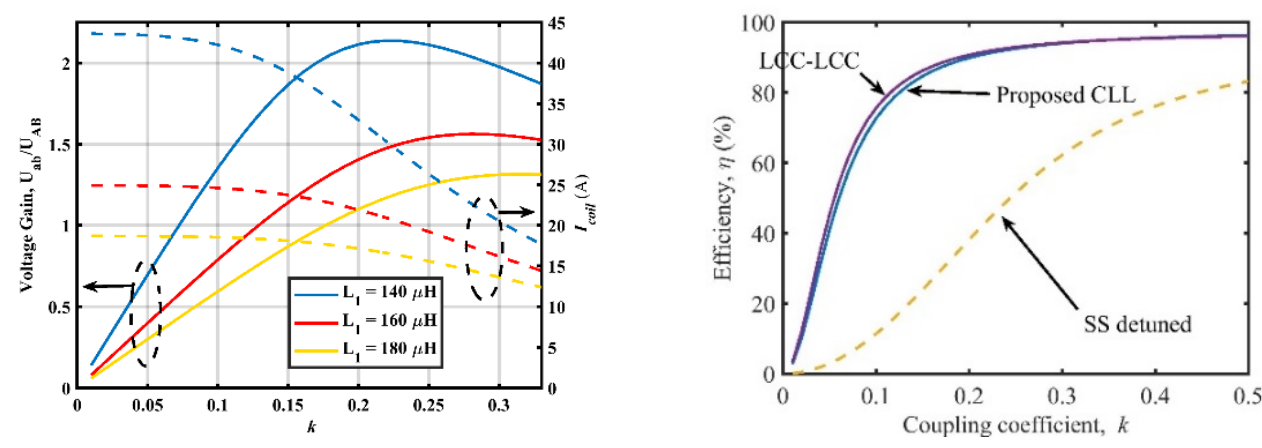

Figure 8. Voltage gain at three different parameters of $L_{l}$ (left) and Comparison of Efficiency between proposed CLL/S, double-sided LCC and SS detuned (right)

\section{CONCLUSION}

This paper proposed a detuned compensation network to solve the overcurrent issue at MOSFETs inverter during uncoupled and high resistor load conditions while maintaining soft switching. From mutual inductance equivalent circuit model study, the primary coil current influence the voltage excitation level at the receiver coil where the current increases tremendously at weak coupling and high load resistor value. This circumstance can cause MOSFETs inverter failure if the input current exceeds its maximum current rating. The proposed CLL compensation at the primary side can constrain the input current by adjusting the compensation inductor. The simulation analysis indicates that the compensation inductor value must be higher than the self-inductance coil for ZVS operation in MOSFET. In terms of efficiency, the proposed compensation offers better efficiency than detuned series-series compensation and almost equivalent to double-sided LCC compensation efficiency.

\section{ACKNOWLEDGEMENTS}

This work was supported by the Ministry of Higher Education (MOHE) under Fundamental Research Grant Scheme (FRGS) and Universiti Teknologi PETRONAS (UTP).

\section{REFERENCES}

[1] K. A. Kalwar, M. Aamir, and S. Mekhilef, "Inductively coupled power transfer (ICPT) for electric vehicle charging - A review,” Renewable and Sustainable Energy Reviews, vol. 47, pp. 462-475, 2015.

[2] K. Aditya, V. K. Sood, and S. S. Williamson, "Magnetic Characterization of Unsymmetrical Coil Pairs Using Archimedean Spirals for Wider Misalignment Tolerance in IPT Systems," IEEE Transactions on Transportation Electrification, vol. 3, no. 2, pp. 454-463, 2017.

[3] Z. Bi, T. Kan, C. Chris, Y. Zhang, Z. Zhao, and G. A. Keoleian, "A review of wireless power transfer for electric vehicles : Prospects to enhance sustainable mobility," Applied Energy, vol. 179, pp. 413-425, 2016.

[4] D. Patil et al., "Wireless Power Transfer for Vehicular Applications : Overview and Challenges," vol. 4, no. 1, pp. 3-37, 2018.

Int J Pow Elec \& Dri Syst Vol. 10, No. 4, Dec 2019 : $2173-2181$ 
[5] A. Ali, M. N. Yasin, M. F. C. Husin, and N. A. A. Hambali, "Design and analysis of 2-coil wireless power transfer (WPT) using magnetic coupling technique," International Journal of Power Electronics and Drive Systems (IJPEDS), vol. 10, no. 2, p. 611, 2019.

[6] Y. H. Sohn, B. H. Choi, E. S. Lee, G. C. Lim, G. H. Cho, and C. T. Rim, "General Unified Analyses of TwoCapacitor Inductive Power Transfer Systems: Equivalence of Current-Source SS and SP Compensations," IEEE Transactions on Power Electronics, vol. 30, no. 11, pp. 6030-6045, 2015.

[7] Z. U. Zahid et al., "Modeling and control of series-series compensated inductive power transfer system," IEEE Journal of Emerging and Selected Topics in Power Electronics, vol. 3, no. 1, pp. 111-123, 2015.

[8] P. Spanik, M. Frivaldsky, M. Piri, and V. Kindl, "Wireless power transfer system with reduced voltage stress on compensation capacitors," IECON Proceedings (Industrial Electronics Conference), pp. 1190-1195, 2016.

[9] B. Esteban, M. Sid-ahmed, N. C. Kar, and S. Member, "A Comparative Study of Power Supply Architectures in Wireless EV Charging Systems," IEEE Transactions on Power Electronics, vol. 30, no. 11, pp. 6408-6422, 2015.

[10] W. Zhang and C. C. Mi, "Compensation topologies of high-power wireless power transfer systems," IEEE Transactions on Vehicular Technology, vol. 65, no. 6, pp. 4768-4778, 2016.

[11] Y. Wang, "An LC / S Compensation Topology and Coil Design Technique for Wireless Power Transfer," vol. 33, no. 3, pp. 2007-2025, 2018.

[12] Y. Wang, H. Wang, T. Liang, X. Zhang, D. Xu, and L. Cai, "Analysis and design of an LCC/S compensated resonant converter for inductively coupled power transfer," 2017 IEEE Transportation Electrification Conference and Expo, Asia-Pacific, ITEC Asia-Pacific 2017, pp. 0-4, 2017.

[13] Y. Wang, Y. Yao, X. Liu, and D. Xu, "S/CLC Compensation Topology Analysis and Circular Coil Design for Wireless Power Transfer," IEEE Transactions on Transportation Electrification, vol. 3, no. 2, pp. 496-507, 2017.

[14] H. Hao, G. A. Covic, and J. T. Boys, "An approximate dynamic model of LCL-T-based inductive power transfer power supplies," IEEE Transactions on Power Electronics, vol. 29, no. 10, pp. 5554-5567, 2014.

[15] S. Li, W. Li, J. Deng, T. D. Nguyen, and C. C. Mi, "A Double-Sided LCC Compensation Network and Its Tuning Method for Wireless Power Transfer," IEEE Transactions on Vehicular Technology, vol. 64, no. 6, pp. 2261-2273, 2015.

[16] A. H. M. Dobi, M. R. Sahid, and T. Sutikno, "Overview of soft-switching DC-DC converters," International Journal of Power Electronics and Drive Systems, vol. 9, no. 4, pp. 2006-2018, 2018.

[17] Y.-C. Hsieh, Z.-R. Lin, M.-C. Chen, H.-C. Hsieh, Y.-C. Liu, and H.-J. Chiu, "High-Efficiency Wireless Power Transfer System for Electric Vehicle Applications," IEEE Transactions on Circuits and Systems II: Express Briefs, vol. 64, no. 8, pp. 942-946, 2017.

[18] M. Kim, D. M. Joo, and B. K. Lee, "Design and Control of Inductive Power Transfer System for Electric Vehicles Considering Wide Variation of Output Voltage and Coupling Coefficient," IEEE Transactions on Power Electronics, vol. 34, no. 2, pp. 1197-1208, 2019.

[19] M. A. N. Bin Kasiran, A. Bin Ponniran, A. B. A. Bakar, and M. H. Bin Yatim, "4-Level Capacitor-Clamped Boost Converter With Hard-Switching and Soft-Switching Implementations," International Journal of Power Electronics and Drive Systems, vol. 10, no. 1, pp. 288-299, 2019.

[20] T. Diekhans and R. W. De Doncker, "A Dual-Side Controlled Inductive Power Transfer System Optimized for Large Coupling Factor Variations and Partial Load," IEEE Transactions on Power Electronics, vol. 30, no. 11, pp. 6320-6328, 2015.

[21] H. Feng, T. Cai, S. Duan, X. Zhang, H. Hu, and J. Niu, "A Dual-Side-Detuned Series-Series Compensated Resonant Converter for Wide Charging Region in a Wireless Power Transfer System," IEEE Transactions on Industrial Electronics, vol. 65, no. 3, pp. 2177-2188, 2018.

[22] H. S. M. Driver, "Research on Overcurrent Detection and Protection of," IECON 2018 - 44th Annual Conference of the IEEE Industrial Electronics Society, vol. 1, pp. 1471-1476.

[23] Q. Zhu, L. Wang, and C. Liao, "Compensate Capacitor Optimization for Kilowatt-Level Magnetically Resonant Wireless Charging System,” IEEE Transactions on Industrial Electronics, vol. 61, no. 12, pp. 6758-6768, 2014.

[24] H. Li, J. Li, K. Wang, W. Chen, and X. Yang, "A maximum efficiency point tracking control scheme for wireless power transfer systems using magnetic resonant coupling," IEEE Transactions on Power Electronics, vol. 30, no. 7, pp. 3998-4008, 2015.

[25] Z. Li, K. Song, J. Jiang, and C. Zhu, "Constant Current Charging and Maximum Efficiency Tracking Control Scheme for Supercapacitor Wireless Charging," IEEE Transactions on Power Electronics, vol. 33, no. 10, pp. 9088-9100, 2018.

[26] C. Li et al., "A Novel Compensation Topology for Inductively Coupled Power Transfer," in 42 Annual conference of the IEEE industrial Electronics society, IECON 2016, no. 1, pp. 2-6, 2016.

[27] G. Buja, M. Bertoluzzo, and K. N. Mude, "Design and Experimentation of WPT Charger for Electric City Car," vol. 62 , no. 12 , pp. 7436-7447, 2015. 